\title{
Comparing TOPEX TEC measurements with IRI predictions
}

\author{
Y.O. Migoya Orué ${ }^{\mathrm{a}, *}$, S.M. Radicella ${ }^{\mathrm{b}}$, P. Coïsson ${ }^{\mathrm{b}}$, R.G. Ezquer ${ }^{\mathrm{a}, \mathrm{c}, \mathrm{d}}$, B. Nava ${ }^{\mathrm{b}}$ \\ ${ }^{a}$ GASuR, Facultad Regional Tucumán, Universidad Tecnológica Nacional, Rivadavia 1050, 4000 S. M. de Tucumán, Argentina \\ ${ }^{\mathrm{b}}$ ARPL, Aeronomy and Radiopropagation Laboratory, ICTP, Via Beirut 7, Trieste, Italy \\ ${ }^{\mathrm{c}}$ Laboratorio de Ionósfera, Dto. de Física, Universidad Nac. de Tucumán, Independencia 1800, 4000 S. M. Tucumán, Argentina \\ ${ }^{\mathrm{d}}$ CONICET, Rivadavia 1917, 1033 Capital Federal, Argentina
}

Received 26 April 2007; received in revised form 7 August 2007; accepted 26 September 2007

\begin{abstract}
TEC values obtained from TOPEX satellite were compared with the International Reference Ionosphere (IRI) 2001 model estimates. The present work also shows results of the IRI model with the option of a new topside electron density distribution (NeQuick model). TOPEX TEC measurements, which include years of high and middle to low solar activity (2000 and 2004), were analyzed by binning the region covered by the satellite $\left( \pm 66^{\circ}\right)$ every five degrees of modip. In general, there is good agreement between IRI predictions and Topex measurements. Cases with large disagreements are observed at low and high latitudes during high solar activity. Comparing the model predictions using the default IRI2001 model and the NeQuick topside option show that the default IRI 2001 version represents the observed data in a more realistic way, but appears to be less reliable at high and low latitudes in some cases.
\end{abstract}

(C) 2008 COSPAR. Published by Elsevier Ltd. All rights reserved.

Keywords: Ionosphere; TEC; Satellite altimetry; Ionospheric models; TOPEX/POSEIDON

\section{Introduction}

TOPEX/POSEIDON (T/P) has provided a large amount of estimates for the sea surface height (SSH). Its altitude of $1336 \mathrm{~km}$ and an inclination angle of $66^{\circ}$ permit to cover the region between $\pm 66^{\circ}$ of the world's oceans in each 9.916 day period (10-day cycles). This joint mission of the National Aeronautics and Space Administration (NASA) and the French Space Agency, Centre National d'Etudes Spatiales (CNES) was the first to carry out a dual-frequency radar altimeter, operating simultaneously at $13.6 \mathrm{GHz}$ ( $\mathrm{Ku}$ band) and $5.3 \mathrm{GHz}$ (C band). The sea surface height measured by the T/P is corrected for atmospheric effects (like ionosphere and wet and dry troposphere), and the retrieval observed by the dual-frequency altimeter constitutes a direct way to estimate the range delay by ionospheric causes (Fu et al., 1994). Thus,

\footnotetext{
${ }^{*}$ Corresponding author.

E-mail address: ymigoyaorue@gmail.com (Y.O. Migoya Orué).
}

the total electron content (TEC) can be obtained as a byproduct that is directly calculated from the ionospheric range delay.

TEC data are very suitable for the analysis of ionospheric climatology and, as done in the present study, for the validation of ionospheric models. TEC data sets, like other $\mathrm{T} / \mathrm{P}$ products, are available in the public domain through the Physical Oceanography Distributed Archive Center (PO.DAAC) at the NASA Jet Propulsion Laboratory (JPL), and are also distributed by Aviso, a key element of the SSALTO Multimission (Segment Sol multimissions d'ALTimétrie, d'Orbitographie et de localisation précise), developed by CNES.

There have been several studies comparing $\mathrm{T} / \mathrm{P}$ and IRI TEC. The results showed, in general, cases with good agreement between modeled and measured VTEC values (Bilitza et al., 1996; Zhao et al., 2004), and considerable underestimation and overestimation of IRI for other cases (Codrescu et al., 2001; Meza et al., 2002; Orús et al., 2002). In order to extend these studies we compared T/P TEC 
measurements and IRI TEC predictions using two options in IRI, the standard 2001 version of IRI and the NeQuick option for the IRI topside.

\section{Models and data}

\subsection{IRI 2001}

The International Reference Ionosphere (IRI) (Bilitza, 1990) is a well-known climatological model widely used and adopted as a point of reference for other models. It is sponsored by the Committee on Space Research (COSPAR) and the International Union of Radio Science (URSI), and supported and continuously updated by NASA/NSSDC. IRI describes the electron density and temperature, ion temperature and composition in the altitude range from about 50 to about $2000 \mathrm{~km}$, and also pro- vides the total electron content (TEC). IRI2001 is the latest available version of this international standard ionosphere (Bilitza, 2001) and is available from its ftp site: ftp:// nssdcftp.gsfc.nasa.gov/models/ionospheric/iri/iri2001/.

\subsection{NeQuick}

NeQuick is an ionospheric electron density model, known as a "profiler", developed at the Aeronomy and Radiopropagation Laboratory (ARPL) of The Abdus Salam International Centre for Theoretical Physics (ICTP), Trieste, Italy and the Institute for Geophysics, Astrophysics and Meteorology (IGAM) of the University of Graz, Austria. It has been adopted for ionospheric specifications by the European Space Agency, European Geostationary Navigation Overlay System (EGNOS) project, and by the
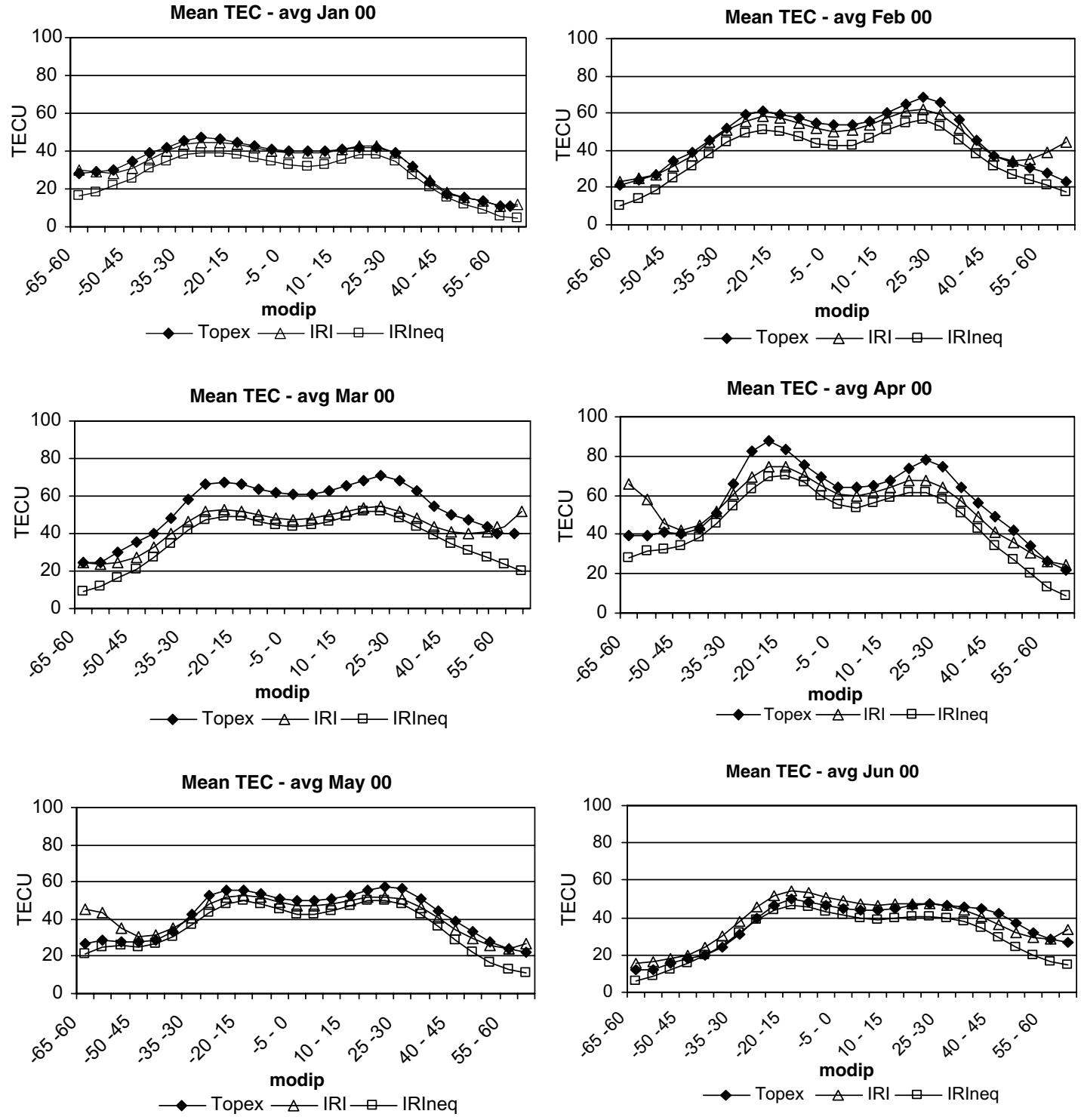

Fig. 1. Averaged T/P TEC data, IRI and IRI (NeQuick option) TEC predictions year 2000. 



Fig. 1 (continued)

ITU-R recommendations as a suitable method for ionospheric applications.

This quick-run model is able to give the electron density distribution on the bottom and top sides of the ionosphere and also to calculate both vertical or slant TEC for any specified ray path for a given height, date, time, geographic latitude and longitude. (Radicella and Zhang, 1995; Radicella and Leitinger, 2001).

\subsection{TOPEX data}

For comparison reasons we used T/P TEC data obtained for one year of high solar activity (HSA) corresponding to year 2000 (T/P cycles 269-305) and one year of moderate to low solar activity (LSA) corresponding to year 2004 (T/P cycles 416-453). The T/P dataset provides TEC values every second this means almost a half million records per cycle.

\section{Results}

The IRI model was evaluated for the locations and times for which T/P TEC data were available in the years 2000 and 2004. Furthermore, electron density and TEC values were computed up to the height of the satellite, $1336 \mathrm{~km}$. Even though these models have been conceived to represent median values of the electron density as a function of the monthly mean of the solar radio flux (F10.7 cm, or the monthly mean sunspot number) in this study, in an attempt to describe TEC estimates for actual conditions (to be compared to T/P measurements), IRI and IRI (with NeQuick topside) are driven by daily sunspot numbers (Coïsson and Radicella, 2004; Coïsson et al., 2006; Hochegger et al., 2000).

This study focuses on the global and 10-day cycle-averaged T/P TEC measurements in comparison with IRI and IRI (NeQuick topside) values calculated with the same procedure. In order to examine spatial variations of the $\mathrm{T} / \mathrm{P}$ 
TEC and IRI model values, we binned the data into 26 modified dip angle (modip) bands, dividing the latitudes covered by the satellite every $5^{\circ}$ of modip from $-66^{\circ}$ to $+66^{\circ}$. The measured and computed TEC values were averaged for each modip band, processed by each cycle (269305 and 416-453). Cycles with large amount of missing data have been rejected.

The T/P observations and the predictions of IRI and IRI (topside NeQuick) were examined by cycle and by month to detect differences in the models analyzed as shown in Figs. 1 and 2. As in previous studies, where IRI model and T/P dual-frequency measurements have been compared, good agreement is found in general.

For the periods of high solar activity, most of the cases we have studied indicate an underestimation by the IRI models, particularly at the crest of the equatorial anomaly (Codrescu et al., 2001; Meza et al., 2002; Orús et al., 2002).
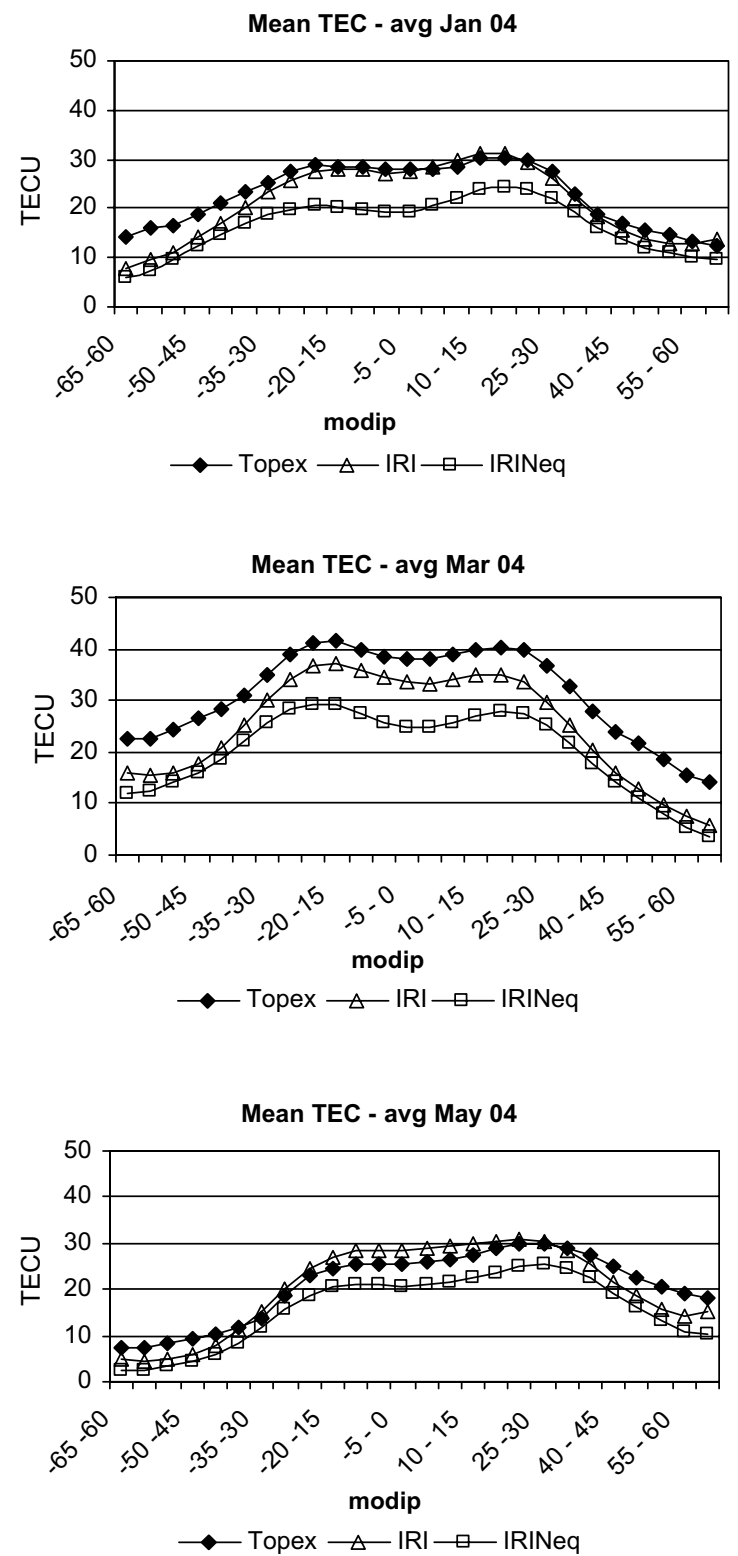

As can be seen from Fig. 1, the IRI2001 and IRI (NeQuick topside) estimates are consistently lower than the T/P measurements during HSA. In some cases both model versions underestimate the magnitude of the equatorial anomaly crest by up to $\sim 20 \mathrm{TECu}$ (see Apr00, Sep00, Oct00, Nov00 in Fig. 1). Near the auroral zones the IRI2001 values occasionally present large discrepancies, especially in Feb00, Mar00, Apr00, May00, Aug00, Sep00, Oct00 (Fig. 1), which are not shown by IRI (NeQuick). In contrast, the IRI (NeQuick) predictions frequently show too low values at high latitudes.

For low solar activity, Codrescu et al. (2001), Orús et al. (2002), and reported that IRI2001 overestimates TEC. Our comparisons show a different behavior, however. Fig. 2 indicates that the IRI2001 predictions are fairly close to or slightly less than the T/P measurements with the exception of May04 and Jun04 (Fig. 2). IRI (NeQuick topside),
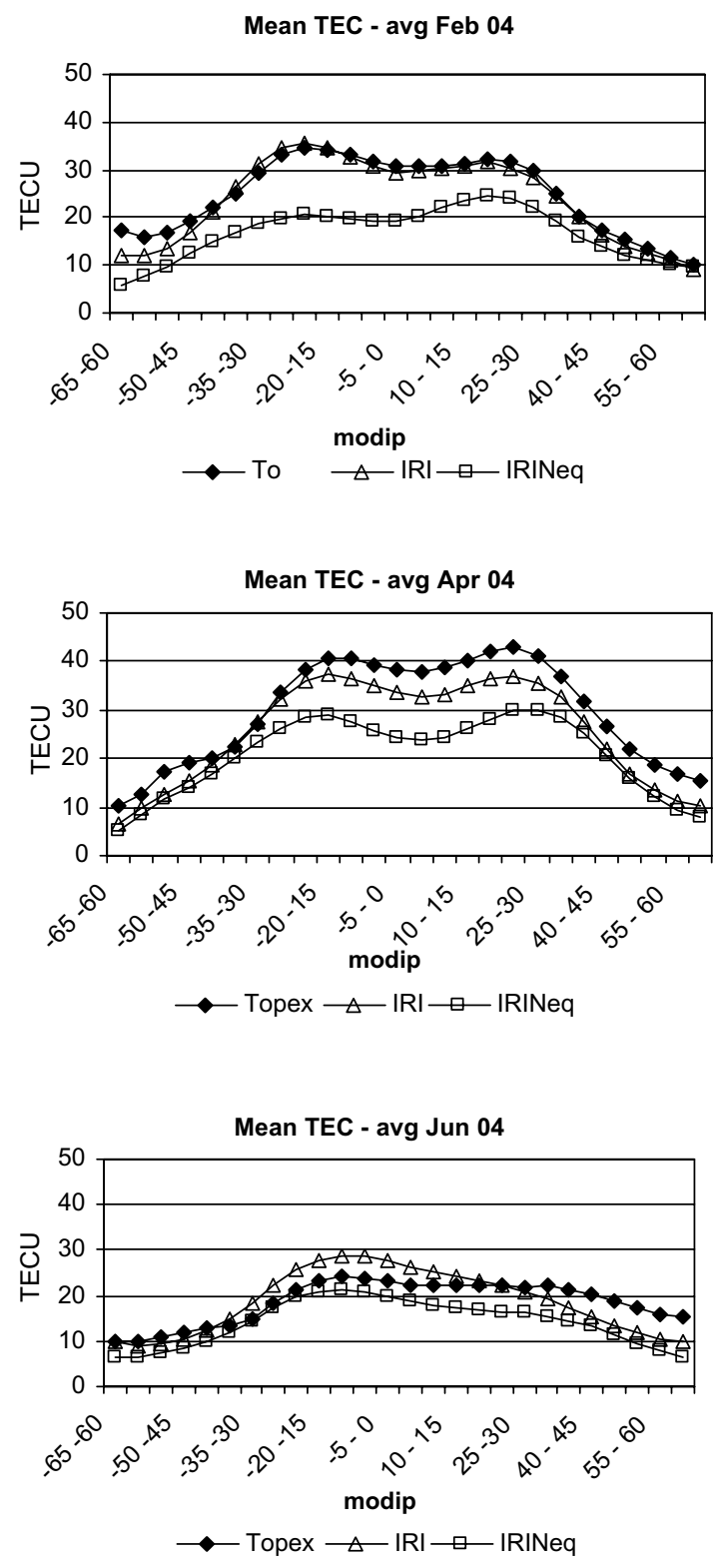

Fig. 2. Averaged T/P TEC data, IRI and IRI (NeQuick option) TEC predictions year 2004. 

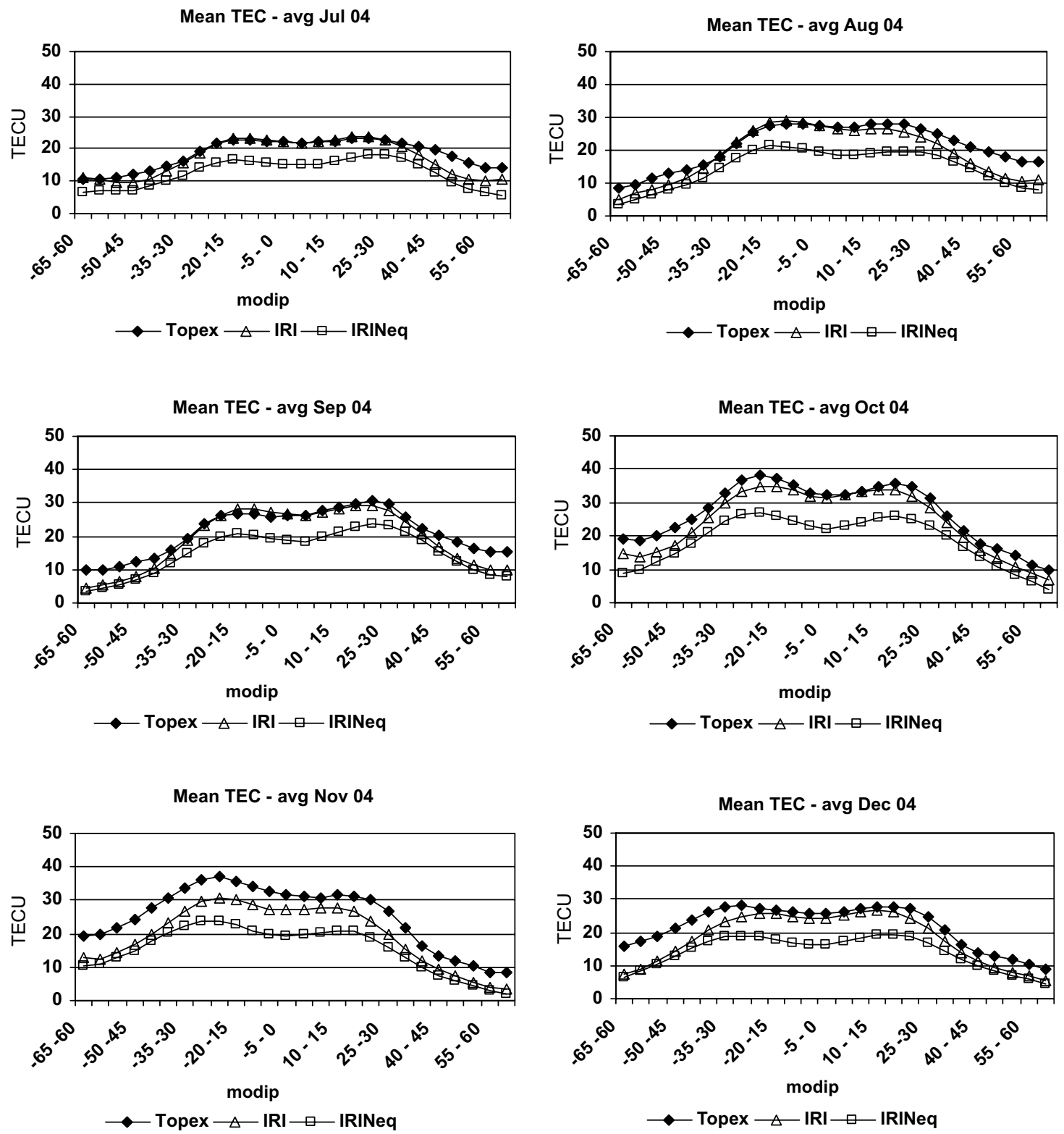

Fig. 2 (continued)

on the other hand, consistently underestimates the TEC values.

\section{Conclusions}

IRI2001 and the NeQuick option for the IRI topside have been compared with TOPEX dual-frequency measurements of TEC during high and moderate to low solar activity (T/P cycles $269-305$ of year 2000 , and T/P cycles $416-453$ of 2004).

The curves for both models are almost perfectly parallel to the $\mathrm{T} / \mathrm{P}$ measurements curve, in some cases with deviations that depend on season. The disagreements are more pronounced in equinoctial conditions.

IRI2001 values for high solar activity compared with those of $\mathrm{T} / \mathrm{P}$ tend to be greater near to auroral zones, and then is clear that in some cases for high and low latitudes IRI (NeQuick) is less dependent on solar activity than IRI2001.

The observed disagreements between predictions and measurements could arise because $\mathrm{NmF} 2$ or the shape of the $\mathrm{N}$ profile, or both, is not well predicted by the model.

In order to propose improvements in IRI and NeQuick models, further additional test and investigations, including studies of the LT dependence, are needed.

\section{Acknowledgement}

Support of Y.O. Migoya Orué for this study was provided by a TRIL (Training and Research in an Italian Laboratory) grant to work in the ARPL, ICTP, Trieste, Italy. 


\section{ARTICLE IN PRESS}

\section{References}

Bilitza, D. International Reference Ionosphere, Rep. NSSDC/WDC-R\& S 90-22. National Space Science Data Center/World Data A for Rockets and Satellites, 1990.

Bilitza, D., Koblinsky, C., Zia, S. The equator anomaly region as seen by the Topex/Poseidon satellite. Adv. Space Res. 18 (6), 23-32, 1996.

Bilitza, D. International reference ionosphere. Radio Sci. 36 (2), 261-275, 2001.

Codrescu, M.V., Beierle, L.K., Fuller-Rowell, T.J., Palo, S.E., Zhang, X. More total electron content climatology from TOPEX/Poseidon measurements. Radio Sci. 36, 325-333, 2001.

Coïsson, P., Radicella, S.M. The IRI topside parameters. Adv. Radio Sci. 2, 249-251, 2004.

Coïsson, P., Radicella, S.M., Leitinger, R. Topside electron density in IRI and NeQuick: features and limitations. Adv. Space Res. 37, 937-942, 2006.
Fu, L., Christensen, E., Yamarone, C. TOPEX/POSEIDON mission overview, J. Geophys. Res. 99 (C12) 24, 369-381, 1994.

Hochegger, G., Nava, B., Radicella, S.M. A family of ionospheric models for different uses. Phys. Chem. Earth 25 (4), 307-310, 2000.

Meza, A.M., Brunini C.A., Bosch W., VanZele, M.A. Comparing vertical total electron content from GPS, Bent and IRI models with TOPEXPoseidon. Adv. Space Res. 30 (2) 401-406 (6), 2002.

Orús, R., Hernández-Pajares, M., Juan, J.M., Sanz, J., García-Fernández, M. Performance of different TEC models to provide GPS ionospheric corrections. J. Atmos. Solar Terr. Phys. 64 (18), 2055-2062, 2002.

Radicella, S.M., Zhang, M.L. The improved DGR analytical model of electron density height profile and total electron content in the ionosphere. Annali di Geofisica XXXVIII (1), 35-41, 1995.

Radicella, S.M., Leitinger, R. The evolution of the DGR approach to model electron density profiles. Adv. Space Res. 27 (1), 35-40, 2001.

Zhao, C., Shum, C.K., Yi, Y., Ge, S., Bilitza, D., Callahan, P. Accuracy assessment of the TOPEX/Poseidon ionosphere measurements. Mar. Geod. 27, 729-739, 2004. 